\title{
Construction and Implementation Based on Curriculum Guided by Work Process
}

\author{
Weijie Gou ${ }^{1,2, a ~ *, D a w e i ~ Y a n g ~}{ }^{2, b}$ and Lihong Wang ${ }^{1, c}$ \\ ${ }^{1}$ Beijing Polytechnice, Beijing 100176,China \\ ${ }^{2}$ Tianjin University of Technology and Education University, Tianjin 300222, China \\ agvjie@126.com, b13207592943@163.com, cwlhjane@126.com
}

Keywords: Work-Process orientation; Integration of theory and practice; Curriculum construction

\begin{abstract}
The curriculum construction of the work process-oriented integration of theory and practice, focuses on the vocational abilities training of professional positions; curriculum contents are combined with position requirements, the content of the course is based on the analysis of real products and production process, and based on the principles of action-oriented designing teaching methods. Through the professional description of experts from enterprises, work process and work tasks of professional positions are determined, on this basis we identify and describe the typical work tasks, and transform them into the corresponding learning areas.
\end{abstract}

\section{Introduction}

School-enterprise cooperation is the future trend, this paper uses the core curriculum of the major of the automobile manufacturing and assembly-- production of Unimog car model as the carrier, through production process of completing a real product, students learn the knowledge which work process needs, master operational skills, and through the process of self-learning train their methods ability and social capacity, to achieve active construction of knowledge, ability and quality. The course is integrated into new ideas and methods of vocational education, from the choice of teaching carrier, curriculum design to classroom teaching and specific implementation of practical operation. In teaching curriculum construction of the work process-oriented learning areas is explored.

\section{Work-oriented Curriculum System}

As a school-enterprise cooperation course, to accurately describe career orientation and training objectives of the major of the automobile manufacturing and assembly, to meet the needs of enterprises and school teaching, to promote to develop systematic curriculum of learning field, under the cooperation of three parties of German Mercedes-Benz experts, Beijing Benz and school, combined with the needs of Beijing Benz companies, work process and work tasks of position of car assembly are analyzed, on this basis typical tasks are identified and descried, and transform them into the corresponding learning areas, the professional curriculum system based on the work process of the major of automotive manufacturing and assembly is determined as the following nine aspects: mechanical mapping and drawing, metal materials and heat treatment, bench skills, lathe skills, milling skills, sheet metal stamping, car welding, vehicle assembly, car spraying.

In the curriculum of this learning system, a full set of Unimog model parts drawings are provided by the German Mercedes-Benz International Training Department. Through making "Unimog Model Car" and using the course of learning area ---"Metalworking Skill Training" as support course, the training of above 9 professional abilities is completed. We train workers of sheet metal stamping, car welding, vehicle assembly, car spray assembly for the Beijing Benz. "Metal processing skills training" is a course of work-oriented and integration of theory and practice. During teaching we should not only to complete teaching the relevant theoretical courses of, but also complete the relevant skills training. Through learning the course students can master the basic metal processing skills, lay the foundation for future job training, be capable of the work car production assembly line. 


\section{Principles of Constructing Work-oriented Curriculum}

Cultivating Concept of Emphasizing Both Professional and Non-professional Ability. Professional skills: This course is based on the production of "Unimog" car model, During the process of manufacturing, processing and assembling parts, students learn the theory of mechanical manufacturing, master the skills and methods of metal processing and parts assembly and adjustment. In this process, students can learn the basic knowledge of mechanical drawing and mechanical transmission, and knowledge of metal craft, tolerance fit and technical measurement, lathe, milling, bench, sheet metal processing and welding, etc. We focus on training students' methods and ideas to analyze and solve practical problems, and lay a good foundation for the future work.

Social ability: to cultivate students learn to be a man - to establish a healthy interpersonal relationship; learn to cooperate - the ability to communicate with people and have team spirit; the correct attitude of life - dedicated work style.

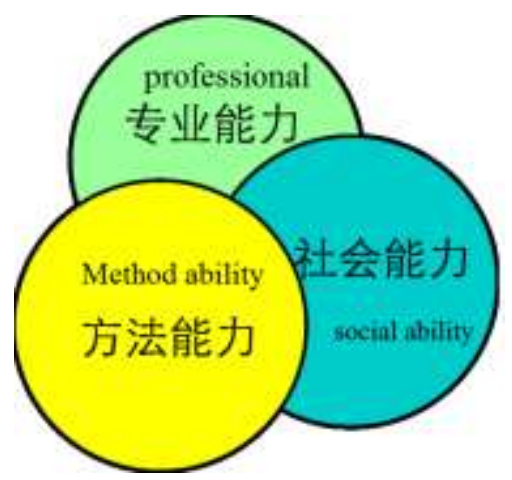

Figure 1. the relationship among the three capabilities

Method ability: to cultivate students learn how to learn - quality of modest and eager to learn and ability to learn independently; learn to work - good style of diligent thinking, doing things seriously; scientific thinking - consciousness of eclectic and innovation.

The relationship among the three capabilities is shown in Figure 1. Method ability is considered as the focus, social ability and professional ability followed.

Train students' non-professional ability and professional ability, during the teaching process students' professional and non-professional ability will be treated equally, each accounts for $50 \%$. At the beginning of the entrance, the school focused on cultivating students 'non-professional ability. In teaching, teachers use various teaching methods to cultivate students' non-professional ability, especially the ability of team cooperation and autonomous learning, and then carry out professional ability training. The proportion of non-professional and professional competencies is shown in Figure 2.

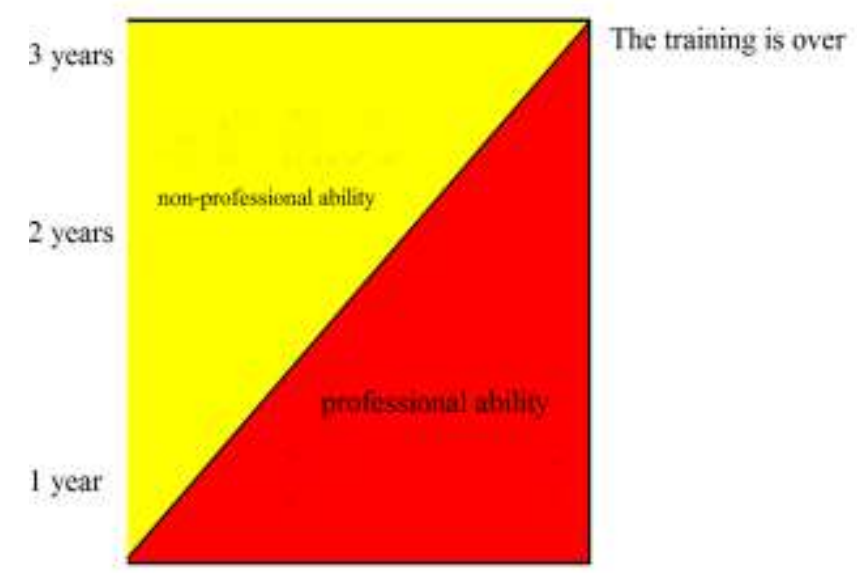

Figure 2 Proportion of non-professional and professional competencies

Design teaching methods based on the principle of action-oriented teaching. Implement the principle of action-oriented teaching, adhere to the unity of "teaching, learning and making", use the 
teaching model of "integration of theory and practice". According to the characteristics of the course, in teaching process case teaching, teaching, project (task)-driving teaching, on-site teaching, heuristic teaching and other methods are used. Adhere to alternation of engineering and teaching, teaching places are classrooms of integration of theory and practice and off-campus enterprises combined. In two years of school study, each student not only completes learning the relevant theory, but also completes production of a "Unimog car model", which fully embodies the teaching mode of integration of theory and practice "learn in work, work in learning".

Course objectives combined with job requirements. Course objectives set are combined as much as possible with the requirements of professional positions, through learning production of "Unimog car model", students can get occupational skills identification of lathe, milling, bench, welding and other types of work.

\section{Implementation of Teaching Activities in Learning Field}

Application of Six-step Teaching. Work-oriented courses are generally courses of integration of theory and practice, teaching process generally uses project teaching method as the main body. The main features of the project teaching method is to emphasize division of labor and cooperation of many people, and independently making and implementing plan, pay attention to make use of project management strategies and project quality-control methods. Acquire knowledge and related skills (quality) in the implementation of the project. The project carrier selected in each learning situation is the work object which is divided into a number of small tasks, allocate time and make plan according to six-step method of "consultation, planning, decision-making, implementation, inspection and assessment," Follow the such a complete "action" process sequence "information, planning, decision making and implementation, inspection, evaluation"

Action-oriented refers to vocational education teaching model of taking behavior or work tasks as the leading direction. The fundamental meaning is that the student is the center of the learning process. The teacher is the organizer and the coordinator of the learning process. In the teaching, the teacher and the student interact with each other. The teacher should give the students the opportunity to self-study and cultivate the students' ability of autonomous learning. In the whole teaching sequence, the teacher should play the role of organizer participant. Allow students to obtain information independently, develop plans independently, implement plans independently, examine learning outcomes independently, and teachers participate in students' learning during the part of decision-making and evaluation. By allowing students to practice, they can "master" vocational skills, learning expertise, and thus build their own experience and knowledge system.

Learning Strategies of Gradual Strategies. According to the progressive learning rules and the degree of difficulty of project carrier selected in specific learning situation, the specific implementation of the course can be set up three levels. These three levels are based on the thinking of learning in practice, according to the difference degree of difficulty

Oriented learning: At the beginning of the curriculum, teachers guide students to understand various operations and work processes, disassemble work tasks and processes, students develop their own work plan; and then teachers guide students to clear the specific tasks of each stage, make targeted knowledge link, form goal orientation; discuss problems met in the course, and make exemplary operation and technical explanation, to guide students to link experience-type the knowledge systematize them, and thus form problems and new knowledge.

Autonomous learning: Implement work tasks and work plan formed in the previous stage according to work process and procedure. In the implementation, each individual or a group, as a unit, completes specific tasks. The most important help to the students is the instruction manual, in which there are problems that may appear in the course of general work and practice. These problems are presented in chapter- form according to the work process, and very targeted.

Workplace Realistic Learning: Completely simulate a real work scenario or enter a productive unit to work and practice. This process is carried out through students' organization and cooperation, planning and assignment, that is, students organize and implement independently. In this process, teacher or 
factory master play the role of giving-tasks and supervisor, students play the role of actual operators or technical workers.

In the actual teaching, according to the teaching requirements of learning field, teachers refine the typical work tasks, students complete the tasks independently or by group cooperation, in the process students will learn various theoretical knowledge and practice which his major needs and some contents about business management, to cultivate and train students' non-professional ability (team cooperation ability, language expression ability, communication ability with people, active self-study ability, self-control ability, professional quality, etc.)

\section{Conclusion}

In action-oriented teaching, with help of putting forward and solving core issues, making decision-work plan and self-examination and evaluation, etc., students are promoted to establish the correct learning motivation continuously, stimulate learning enthusiasm, improve learning consciousness, to achieve the realm of self-learning. Through group work and inquiry learning students promote the development of their coordination and cooperation ability. At the end of each learning unit, students also talk with teachers, teachers give students objective and accurate feedback, so that students learn about the extent of mastering and understanding knowledge, effectively guide for students' future study.

\section{Acknowledgements}

Supported by Program for Research Team in Beijing Polytechnic

\section{References}

[1] Jiang Dayuan. Study on mainstream teaching thought in Contemporary German vocational education [M]. Beijing: Tsinghua University Press, 2007.: 245-260

[2] Zhao Zhiqun. New concepts of Vocational education ,training and learning [M]. Beijing: Science Press, 2007.6: 122-125

[3] [German] Rudolf Pfeiffer. theory and practice of Project teaching [M]. Translator Fu Xiaofang Jiangsu: Jiangsu Education Press, 2007.2: 189-221

[4] Jiang Dayuan. Research and new theory about Vocational education [M]. Beijing: Education Science Press, 2007.10: 53-65

[5] Gou Weijie. Application of Project Teaching Method in "CNC Machine Tool and Application" Course [J]. Mechanical Vocational Education, 2007.7: 49-52 